Original Article

\title{
JACOBSON'S PROGRESSIVE MUSCLE RELAXATION (JPMR) TRAINING TO REDUCE ANXIETY AND DEPRESSION AMONG PEOPLE LIVING WITH HIV
}

\author{
Prameelarani Bommareddi ${ }^{1}$, Blessy Prabha Valsaraj ${ }^{2} \&$ Shalini $^{3}$ \\ ${ }^{1}$ Student M. Sc (N), ${ }^{2}$ Associate Professor, ${ }^{3}$ Assistant Professor, Department of Mental Health Nursing, \\ Manipal College of Nursing M anipal, Manipal University, Manipal - 576 104, Karnataka, INDIA. \\ Correspondence: \\ Prameelarani Bommareddi, \\ D/o Ramachandrareddi Bommareddi, Rudravarun (Post), Reddigudam (Mandal), Krishna (District), Andhra Pradesh, India. \\ Mobile : +9188974 62019, Fax : +918202922572 E-mail : pramilabommareddy@yahoo.com
}

\begin{abstract}
:
Background: The term AIDS refers only to the last stage of the HIV infection. AIDS can be called as our modern pandemic affecting both industrialized and developing countries.

Objectives: To assess the anxiety and depression among people living with HIV as measured by HADS (Hospital Anxiety and Depression Scale), to determine the effectiveness of JPM R in terms of reduction in the mean posttest anxiety and depression scores, to find the association of anxiety and depression among people living with HIV with selected demographic and disease specific variables.

M aterials and M ethods: one group pre test and post test design was used. 30 people living with HIV who were admitted at ART center, District Hospital, Udupi were selected and different scales on anxiety and depression scale for people living with HIV were administered. Purposive sampling technique was used for the study.

Results: Out of 30 subjects, $13.30 \%$ (4) experienced abnormal anxiety and $16.7 \%$ (5) abnormal depression. There was significance difference between mean difference of pretest and post test scores of anxiety $(\mathrm{t}=8.471, \mathrm{df}=29, \mathrm{p}=0.001)$ and depression $(\mathrm{t}=6.811, \mathrm{df}=29$, $p=0.001$ ). Anxiety is independent of the selected variables (Demographic and disease specific). Depression is dependent on previous history of psychiatricillness $(\chi 2=6.584, d f=2, p=0.037)$.
\end{abstract}

Conclusion: JPM R is a simple non-invasive, cost effective method. The result showed that JPM R training had a positive effect in reducing the anxiety and depression and JPM R can be used as an effective alternative therapy.

Keywords: Anxiety, Depression, JPM R and People living with HIV.

\section{Introduction :}

Acquired is obtained or received by a person that does not ordinarily exist within one's body. Immune deficiency is not an isolated disease but one which has a variety of symptoms leading to various disorders and a set of diseases ${ }^{1}$. The acquired immune deficiency syndrome (AIDS) is a fatal illness caused by retro virus known as human immunodeficiency virus (HIV) which breaks down

\begin{tabular}{|c|}
\hline Access this article online \\
\hline Quick Response code \\
\hline \\
\hline
\end{tabular}

the body's immune system, leaving the victim vulnerable to a host of life threatening opportunistic infections, neurological disorders or unusual malignancies ${ }^{2}$. One of the special features of HIV infection is that once infected there is a high probability that a person will be infected for life. The term AIDS refers only to the last stage of the HIV infection. AIDS can be called as our modern pandemic affecting both industrialized and developing countries. Every day, over 6800 persons become infected with HIV and over 5700 people die from AIDS. The HIV pandemic remains the most serious of infectious disease and a challenge to public health. In 2009, 2.6 million people were estimated to became newly infected with $\mathrm{HIV}^{3}$.

Stress is common in people with HIV. Because of this stress they develop anxiety and they will go to depression. Relaxation training is taught as a self control technique that the individual can use to reduce various forms of physiological over arousals that produce somatic 
symptoms. Relaxation training has been used to treat tension, headaches, migraine headaches, asthma, insomnia and hypertension (Lavige and Burns, 1981).

Physical activity is an important means of reducing stress levels and preventing some of its damaging effects on the body. Exercise uses up the adrenaline and other hormones which the body produces under stress and relaxes the muscles. It will help to strengthen the heart and improve blood circulation too.

Vardhana M and Laxminarayana K (2007) conducted a review of article in M anipal, on depression in Patients with HIV/AIDS in India, by comparing ten studies of HIV positive and at risk HIV negative patients. The study stated that safe and effective treatment of major depression, which is one of the most common comorbid conditions in individuals infected with HIV, significantly lowers morbidity and mortality of HIV disease ${ }^{4}$.

Progressive muscle relaxation was developed by Chicago physician Jacobson in the 1920's. Jacobson theorized that anxiety and stress lead to muscle tension which in turn increases feelings of anxiety. When the body is in a relaxed state however, there is little muscle tension leading to decreased anxious feelings. Jacobson believed that one's body is relaxed; one's mind cannot be in a state of angst ${ }^{5}$.

Jacobson's muscle relaxation issimple non invasive and cost effective, method that can be used for promotion of quality of life without any adverse effects. It is known people living with HIV undergo a lot of anxiety and depression. Hence the researcher decided to check the usefulness of Jacobson's progressive muscle relaxation among these subjects.

\section{Materialsand Methods \\ Design}

One group pretest-posttest design

\section{Sample and setting}

Purposive sampling was used to select 30 people living with HIV, from District Hospital at ART center, Udupi.

\section{Data collection}

The study was undertaken in District Hospital at ART center Udupi from 19th December 2011 to 14th January 2012 .The design adopted for this study was one group pre test and post test design. The pre test done on the day 1 for assessing the demographic, disease specific variables and hospital anxiety and depression scale. A continuous ten sessions of supervised practice of JPMR was conducted followed by a post test on day 10 immediately after the practice. Purposive sampling techniques were used. Samples age group between 20-60 years and who were willing to participate in the study. Present study the researcher took the people living with HIV, who were admitted in the District Hospital. Informed consent was taken from the patients. All the tools were filled by the patient.

The scales used were Demographic proforma, Disease specific proforma and Hospital anxiety depression scale for people living with HIV. The demographic proforma was designed to collect the background information of the subjects. It consisted of 11 items. It consists of age, gender, educational status, religion, marital status, type of family, source of income, family income per month (in rupees), current occupation and job change after diagnosis. The subjects were asked to answer using a tick mark in the appropriate space provided on the right side of each item and also fill up the blanks appropriately. The items did not have any scoring as they were meant to collect the factual information.

The disease specific proforma was designed to collect the information about the illness of the subjects. It consists of 6 items. The item includes duration after diagnosis (in years), CD4 count, HIV stages, opportunistic infections, ART side effects and previous history of psychiatric illness. This information is collected from the medical records of the subjects, not from the subjects directly measured by stress scale for people living with HIV.

The Hospital anxiety and depression scale (HADS) was adopted from Zigmond and Snaith $(1983)^{6}$, standardized scale and widely used to find the anxiety and depression of 
patients admitted in the hospitals. The HADS consists a total of 14 items and it is categorized under anxiety and depression. There are 7 items under the anxiety and 7 items under the depression. Which were given a score of three, two, one and zero respectively. The maximum possible score in each area is 21 in both the areas of anxiety and depression, which was arbitrarily divided as 0-7 normal, 8-10 borderline abnormal and 11-21 abnormal.

\section{Data analysis}

Statistical package for social sciences (SPSS 16.0) software was used for statistical analysis of raw data. Frequency, percentage, paired t-test and Chi square test $(\mathrm{p} 0.05)$ ware applied.

\section{Results:}

Background information of the sample characteristics collected using demographic proforma is shown in table 1. Out of 30 subjects, majority $66.7 \%$ (20) subjects belonged to age group of 36-50 years. Equal number of males and females participated i.e. 50\% (15).Most of the samples $33.3 \%$ (10) had only up to primary education, Hindus $46.7 \%$ (14). Maximum 63.3\%(19) samples are married. Maximum $43.3 \%$ (13) samples belonged to nuclear family. All samples were financially supported by self / family members. Family income per month (in rupees) was less than 5,000 for majority i.e. $83.3 \%$ (25). Maximum 76.6\% (23) samples were unskilled workers. Half of the samples changed their job after diagnosis.

Background information of the sample characteristics collected using disease specific proforma is shown in table 2. Out of 30 subjects, the diagnosis made for majority $80 \%$ (24) of people living with HIV within 2 years of duration. M aximum $46.7 \%$ (14) samples were having CD4 count less than 200 . Half of them $50 \%$ (15) belonged to stage II of HIV. Majority $70 \%$ (21) samples were having opportunistic infections. Previous history of psychiatric illness i.e. 43.3\% (13). Many of the subjects $46.7 \%$ (14) were suffering from ART side effects.

Description of anxiety, depression among people living with HIV: Out of 30 subjects $13.30 \%$ (4) experienced abnormal anxiety and $16.7 \%$ (5) abnormal depression and source of maximum information is shown in Figure 1.

Effectiveness of JPM R on anxiety: Since the anxiety scores were following normal distribution, parametric pairedt test was used. It is clear from table 3 , that the p value was 0.001 . The post test scores is reduced compared to the pre test scores of anxiety. JPM R is effective in reducing the anxiety.

Effectiveness of JPM R on depression: Since the depression scores were following normal distribution, parametric paired $\underline{t}$ test was used. It is clear from table 4 , that the $p$ value was 0.001 . The post test scores is reduced compared to the pre test scores of depression. JPM R is effective in reducing the depression.

\section{Association between anxiety with selected demographic variables and disease specific variables: It is clear from} table 5, thatthere was no significant association between anxiety and selected demographic variables and disease specific variables. Concluded that anxiety is independent of the selected variables such as age, gender, educational status, religion, marital status, type of family, source of income, family income per month (in rupees), current occupation, job change after diagnosis, duration after diagnosis, CD4 count, HIV stages, opportunistic infections, ART side effects and previous history of psychiatric illness.

\section{Association between depression with selected demographic variables and disease specific variables: It is} clear from table 6,that there was no significant association between depression and selected demographic variables and disease specific variables except for pervious history of psychiatry illness. This study concluded that depression is independent of the selected variables such as age, gender, educational status, religion, marital status, type of family, source of income, family income per month (in rupees), current occupation and job change after diagnosis, duration after diagnosis, CD4 count, HIV stages, opportunistic infections and ART side effects. This study concluded that depression is dependent on previous history of psychiatricillness $(\chi 2=6.584, d f=2, p=0.037)$. 
Table 1: Frequency and percentage distribution of demographic variables.

\begin{tabular}{|c|c|c|}
\hline Demographic variables & Frequency (f) & Percentage (\%) \\
\hline \multicolumn{3}{|l|}{ Age in years } \\
\hline 20-35 & 10 & 33.3 \\
\hline $36-50$ & 20 & 66.7 \\
\hline \multicolumn{3}{|l|}{ Gender } \\
\hline Male & 15 & 50.0 \\
\hline Female & 15 & 50.0 \\
\hline \multicolumn{3}{|l|}{ Educational status } \\
\hline Illiterate & 8 & 26.7 \\
\hline Primary (1-6 $6^{\text {th }}$ standard) & 10 & 33.3 \\
\hline Secondary $\left(7-10^{\text {th }}\right.$ standard $)$ & 6 & 20.0 \\
\hline PUC and above & 6 & 20.0 \\
\hline \multicolumn{3}{|l|}{ Religion } \\
\hline Hindu & 14 & 14 \\
\hline M uslim & 9 & 9 \\
\hline Christian & 7 & 7 \\
\hline \multicolumn{3}{|l|}{ M arital status } \\
\hline Married & 19 & 63.3 \\
\hline Widowed & 6 & 20.0 \\
\hline Divorced & 5 & 16.7 \\
\hline \multicolumn{3}{|l|}{ Type of family } \\
\hline Nuclear & 13 & 43.4 \\
\hline Extended & 10 & 33.3 \\
\hline Joint & 7 & 23.3 \\
\hline \multicolumn{3}{|l|}{ Source of income } \\
\hline Self / family members & 30 & 100.0 \\
\hline \multicolumn{3}{|l|}{$\begin{array}{l}\text { Family income per month } \\
\text { (in rupees) }\end{array}$} \\
\hline Less than 5,000 & 25 & 83.3 \\
\hline $5001-10,000$ & 5 & 16.7 \\
\hline \multicolumn{3}{|l|}{ Current occupation } \\
\hline Skilled work & 5 & 16.7 \\
\hline Unskilled work & 23 & 76.6 \\
\hline \multicolumn{3}{|l|}{ Job change after diagnosis } \\
\hline Yes & 15 & 50.0 \\
\hline No & 15 & 50.0 \\
\hline
\end{tabular}

$\mathrm{f}=$ frequency, $\%=$ percentage, $\mathrm{n}=$ sample size

Table 2: Frequency and percentage distribution of disease specific variables.

$n=30$

\begin{tabular}{lcc}
\hline Disease specific variables & Frequency(f) & Percentage (\%) \\
\hline Duration after diagnosis ( in years) & & \\
Less than 2 years & 24 & 80.0 \\
Less than 2 years & 6 & 20.0 \\
CD4 count & & \\
Greater than 500 & 5 & 16.7 \\
350 to 200 & 11 & 36.7 \\
Less than 200 & 14 & 46.6 \\
HIV stages & & \\
I & 4 & 13.3 \\
\hline
\end{tabular}

\begin{tabular}{lcc}
\hline Disease specific variables & Frequency(f) & Percentage (\%) \\
\hline II & 15 & 50.0 \\
III & 9 & 30.0 \\
IV & 2 & 6.7 \\
Opportunistic infection & & \\
Yes & 21 & 70.0 \\
No & 9 & 30.0 \\
Previous history of psychiatric illness & & \\
Yes & 13 & 43.3 \\
No & 17 & 56.7 \\
ART side effects & & \\
Yes & 14 & 46.7 \\
No & 16 & 53.3 \\
\hline f=frequency, \%=percentage, & n=sample size
\end{tabular}

\section{Effectiveness of JPMR on anxiety}

Table 3: Mean, Standard deviation, Standard error, Standard deviation difference and $\underline{t}$ value of pretest posttest measurement of anxiety $\quad n=30$

\begin{tabular}{ccccccc}
\hline $\begin{array}{c}\text { Anxiety } \\
\text { score }\end{array}$ & Mean & SD & $\begin{array}{c}\text { Standard } \\
\text { error }\end{array}$ & & df & P value \\
\hline $\begin{array}{c}\text { Pre-test } \\
\text { Post-13 }\end{array}$ & 3.026 & 0.472 & 8.471 & 29 & $0.001 *$ \\
*Significant, $n=$ sample size, df=degree of freedom &
\end{tabular}

\section{Effectiveness of JPMR on depression}

Table 4: Mean, Standard deviation, Standard error, Standard deviation difference and $t$ value of pretest posttest measurement of depression.

$n=30$

\begin{tabular}{ccccccc}
\hline $\begin{array}{c}\text { Anxiety } \\
\text { score }\end{array}$ & Mean & SD & $\begin{array}{c}\text { Standard } \\
\text { error }\end{array}$ \\
\hline $\begin{array}{c}\text { Pre-test } \\
7.83\end{array}$ & 3.354 & 0.617 & 6.811 & 29 & $0.001^{*}$ \\
Post-test & 3.63 & 1.629 & & df & P value \\
*Significant, $n=$ sample size, df=degree of freedom &
\end{tabular}

\section{Discussion :}

The findings of the present study showed that, out of 30 subjects a few of them $13.30 \%$ (4) experienced abnormal anxiety and $16.7 \%$ (5) abnormal depression. Similar findings supports the results of another study conducted by Chandra, Geetha and Sanjeev (2005), HIV and psychiatric disorder in India conducted in a group of 51 seropositive persons in south India by using the Hospital anxiety and depression scale. Out of 51 samples $57 \%$ of the samples scored anxiety disorder. The number of individuals diagnosed as having anxiety disorders in this study was higher ${ }^{7}$. Similar findings support the results of another meta-analysis study conducted by Vardhana et al (2007) in 
Table 5: Chi square test computed between anxiety and selected demographic variables and disease specific variables.

$n=30$

\begin{tabular}{|c|c|c|c|c|c|c|}
\hline Selected variables & Normal & Borderline & Abnormal & Chi-square (x2) & df & $p$ value \\
\hline & & abnormal & & value & & \\
\hline \multicolumn{7}{|l|}{ Age in years } \\
\hline $20-35$ & 8 & 1 & 1 & 0.147 & 2 & 0.929 \\
\hline $36-50$ & 15 & 2 & 3 & & & \\
\hline \multicolumn{7}{|l|}{ Gender } \\
\hline Male & 13 & 1 & 1 & 1.725 & 2 & 0.422 \\
\hline Female & 10 & 2 & 3 & & & \\
\hline \multicolumn{7}{|l|}{ Educational status } \\
\hline Below $10^{\text {th }}$ & 17 & 3 & 4 & 2.283 & 2 & 0.319 \\
\hline Above $10^{\text {th }}$ & 6 & 0 & 0 & & & \\
\hline \multicolumn{7}{|l|}{ Religion } \\
\hline Hindu & 11 & 0 & 3 & 4.799 & 4 & 0.309 \\
\hline Muslim & 7 & 2 & 0 & & & \\
\hline Christian & 5 & 1 & 1 & & & \\
\hline \multicolumn{7}{|l|}{ M arital status } \\
\hline Married & 15 & 2 & 2 & 0.356 & 2 & 0.837 \\
\hline Widowed / Divorced & 8 & 1 & 2 & & & \\
\hline \multicolumn{7}{|l|}{ Type of family } \\
\hline Nuclear & 10 & 1 & 2 & 4.193 & 4 & 0.381 \\
\hline Extended & 9 & 0 & 1 & & & \\
\hline Joint & 4 & 2 & 1 & & & \\
\hline \multicolumn{7}{|c|}{ Family income per month (in rupees) } \\
\hline Less than 5,000 & 19 & 3 & 3 & 0.440 & 2 & 0.803 \\
\hline $5001-10,000$ & 4 & 0 & 1 & & & \\
\hline \multicolumn{7}{|l|}{ Current occupation } \\
\hline Skilled work & 4 & 1 & 1 & 0.494 & 2 & 0.781 \\
\hline Unskilled work & 19 & 2 & 3 & & & \\
\hline \multicolumn{7}{|c|}{ Job change after diagnosis } \\
\hline Yes & 13 & 1 & 1 & 1.725 & 2 & 0.422 \\
\hline No & 10 & 2 & 3 & & & \\
\hline \multicolumn{7}{|c|}{ Duration after diagnosis (in years) } \\
\hline Less than 2 years & 18 & 2 & 4 & 1.023 & 2 & 0.599 \\
\hline Greater than 2 years & 5 & 1 & 0 & & & \\
\hline \multicolumn{7}{|l|}{ CD4 count } \\
\hline Greater than 500 & 3 & 1 & 1 & 1.739 & 4 & 0.784 \\
\hline 350 to 200 & 8 & 1 & 2 & & & \\
\hline Less than 200 & 12 & 1 & 1 & & & \\
\hline \multicolumn{7}{|l|}{ HIV stages } \\
\hline I & 3 & 0 & 1 & 4.653 & 6 & 0.589 \\
\hline II & 11 & 1 & 3 & & & \\
\hline III & 7 & 2 & 0 & & & \\
\hline IV & 2 & 0 & 0 & & & \\
\hline \multicolumn{7}{|l|}{ Opportunistic infection } \\
\hline Yes & 17 & 2 & 2 & 0.945 & 2 & 0.623 \\
\hline No & 6 & 1 & 2 & & & \\
\hline \multicolumn{7}{|l|}{ ART side effect } \\
\hline Yes & 10 & 2 & 2 & 0.594 & 2 & 0.743 \\
\hline No & 13 & 1 & 2 & & & \\
\hline \multicolumn{7}{|c|}{ Previous history of psychiatry illness } \\
\hline Yes & 11 & 0 & 2 & 2.556 & 2 & 0.279 \\
\hline No & 12 & 3 & 2 & & & \\
\hline
\end{tabular}

$\mathrm{n}=$ sample size,$\quad \chi 2=$ chi-square value,$\quad d f=$ degree of freedom 
Table 6: Chi square test computed between depression and selected demographic variables and disease specific variables.

$n=30$

\begin{tabular}{|c|c|c|c|c|c|c|}
\hline Selected variables & Normal & $\begin{array}{l}\text { Borderline } \\
\text { abnormal }\end{array}$ & Abnormal & $\begin{array}{l}\text { Chi-square } \\
\text { (x2) value }\end{array}$ & df & $\mathrm{p}$ value \\
\hline \multicolumn{7}{|l|}{ Age in years } \\
\hline । 20-35 & 5 & 4 & 1 & 0.931 & 2 & 0.628 \\
\hline । $36-50$ & 11 & 5 & 4 & & & \\
\hline \multicolumn{7}{|l|}{ Gender } \\
\hline I Male & 9 & 4 & 2 & 0.561 & 2 & 0.755 \\
\hline I Female & 7 & 5 & 3 & & & \\
\hline \multicolumn{7}{|l|}{ Educational status } \\
\hline I Below $10^{\text {th }}$ & 12 & 8 & 4 & 0.694 & 2 & 0.707 \\
\hline I Above $10^{\text {th }}$ & 4 & 1 & 1 & & & \\
\hline \multicolumn{7}{|l|}{ Religion } \\
\hline I Hindu & 7 & 5 & 2 & 1.621 & 4 & 0.805 \\
\hline I Muslim & 6 & 2 & 1 & & & \\
\hline Christian & 3 & 2 & 2 & & & \\
\hline \multicolumn{7}{|l|}{ Marital status } \\
\hline I Married & 12 & 6 & 1 & 5.024 & 2 & 0.081 \\
\hline I Widowed / Divorced & 4 & 3 & 4 & & & \\
\hline \multicolumn{7}{|l|}{ Type of family } \\
\hline I Nuclear & 6 & 3 & 4 & 6.035 & 4 & 0.197 \\
\hline I Extended & 7 & 2 & 1 & & & \\
\hline I Joint & 3 & 4 & 0 & & & \\
\hline \multicolumn{7}{|c|}{ Family income per month (in rupees) } \\
\hline I Less than 5,000 & 14 & 7 & 4 & 0.440 & 2 & 0.803 \\
\hline । 5001-10,000 & 2 & 2 & 1 & & & \\
\hline \multicolumn{7}{|l|}{ Current occupation } \\
\hline I Skilled work & 3 & 2 & 1 & 0.043 & 2 & 0.979 \\
\hline I Unskilled work & 13 & 7 & 4 & & & \\
\hline \multicolumn{7}{|l|}{ Job change after diagnosis } \\
\hline । Yes & 10 & 3 & 2 & 2.200 & 2 & 0.333 \\
\hline I No & 6 & 6 & 3 & & & \\
\hline \multicolumn{7}{|c|}{ Duration after diagnosis (in years) } \\
\hline $1 \quad$ Less than 2 years & 13 & 8 & 3 & 1.710 & 2 & 0.425 \\
\hline I Greater than 2 years & 3 & 1 & 2 & & & \\
\hline I CD4 count & & & & & & \\
\hline I Greater than 500 & 2 & 2 & 1 & 4.494 & 4 & 0.343 \\
\hline । 350 to 200 & 7 & 1 & 3 & & & \\
\hline I Less than 200 & 7 & 6 & 1 & & & \\
\hline \multicolumn{7}{|l|}{ HIV stages } \\
\hline 11 & 1 & 2 & 1 & 5.266 & 6 & 0.510 \\
\hline | II & 10 & 3 & 2 & & & \\
\hline I III & 4 & 4 & 1 & & & \\
\hline I IV & 1 & 0 & 1 & & & \\
\hline \multicolumn{7}{|l|}{ Opportunistic infection } \\
\hline I Yes & 12 & 6 & 3 & 0.476 & 2 & 0.788 \\
\hline I No & 4 & 3 & 2 & & & \\
\hline \multicolumn{7}{|l|}{ ART side effect } \\
\hline I Yes & 7 & 5 & 2 & 0.430 & 2 & 0.807 \\
\hline I No & 9 & 4 & 3 & & & \\
\hline \multicolumn{7}{|c|}{ Previous history of psychiatry illness } \\
\hline I Yes & 10 & 3 & 0 & 6.584 & 2 & $0.037 *$ \\
\hline I No & 6 & 6 & 5 & & & \\
\hline
\end{tabular}

*Significant $n=$ sample size,$\quad \chi 2=$ chi-square value,$\quad d f=$ degree of freedom 
Fig 1: Bar diagram showing the percentage of anxiety and depression of people living with HIV.

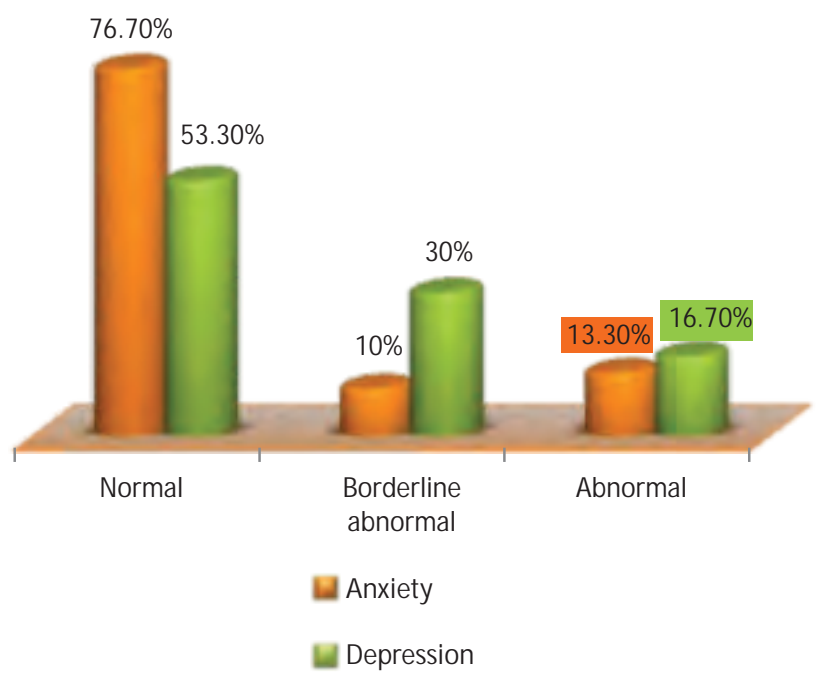

Manipal by comparing the ten studies in South India. It reported that $40 \%$ of seropositive individuals suffering from depression. Anxiety severe enough to fulfill the ICD 10 criteria for generalized anxiety disorder has been found in $90 \%$ of the HIV infected individuals with depressive symptoms were identified.2 0 n the contrary an increase in the rates were reported by Chandra and Vardhana ${ }^{4}$.

In the present study it was observed that the mean post test anxiety and depression scores were significantly lower than the mean post test score which was significant at 0.05 level. The present study finding supports the results of the study conducted by Fukunishi et.al. (2005) conducted a study in Tokyo Metropolitan Komagome Hospital, examined the efficacy of relaxation techniques in a sample of HIV patients without AIDS in the early stages after infection, by comparing the three groups: relaxation group (progressive muscle relaxation and modified autogenic training); ordinary supportive psychotherapy group, and finally no psychiatric treatment group. The sample selected were 19 people living with HIV. Scores for anxiety, fatigue, depression and contusion, as measured by the profile of mood states (POMS), were significantly lower after relaxation than before. There were no significant differences in the POM S scores (except for anger) among the three groups. The results of patients using relaxation showed that difference between pre test and post test (mean $=38.7, S D=7.8, P=\measuredangle 0.05$ ). Results suggest that a combination of progressive muscle relaxation and modified autogenic training is a useful method, which can be easily employed in HIV patients without AIDS. ${ }^{8}$

\section{Conclusion}

People living with HIV were likely to experience abnormal anxiety and depression. JPMR training is effective in reducing the anxiety and depression among people living with HIV.JPMR is a simple non-invasive cost effective, method that can be used for promotion of quality of life without any adverse effects on the people living with HIV.

\section{Acknowledgement}

The authors wish to thanks to Dr. Anice George, Dean, $M$ anipal College of Nursing M anipal and Dr. Suresh Shasthri and Dr. Hegde, District hospital, ART center, Udupi for giving administrative permission to conduct the study.

\section{Reference}

1. HIV/AIDS Basic facts. Karnataka State Prevention Society. M arch 2002; 8-9.

2. Park K. Textbook of preventive and social medicine.21th edition. M/S BanarsidasBhanot Publishers: Jabalpur: India; 2011.

3. Global report. UNAIDS report on the global AIDS epidemic 2010 Available from http:// data.unaids.org/pub/globalreport.

4. SammodVardhana M and BairyLaxminarayana K. Depression in patients with HIV/AIDS. Kasturba Medical College, Manipal and Karnataka, India Kuwait M edical Journal 2007, 39 (3): 227-230.

5. Townsend M C. Psychiatric mental health nursing concept of care 5th edition. Philadelphia: F. A Davis publishers; 2005.

6. Zigmond, A.S, Snaith, R.P. 1983, The Hospital Anxiety and Depression Scale. ActaPsychiatricaScandinavica, vol. 67, pp. 361-370.

7. PrabhaS.Chandra, Geetha Desai and SanjeevRanjan. HIV and psychiatric disorders. Bangalore and Manipal Institute of Higher Education, M anipal, Karnataka, India. 2005.

8. Isao Fukunishi, Takashi Hosaka, Tomoko M atsumoto, M otoko Hayashi, Masayoshi Negishi, Liaison Psychiatry And HIV Infection : Application Of Relaxation In HIV Positive Patients. Regular Article Psychiatry and Clinical Neurosciences (1997), 51, 5-829). 2005; 50: 305-308. 